\title{
Tumor biology as a basis for molecular targeting in cancer
}

\author{
Steven M. Larson · Giuliano Mariani • \\ H. William Strauss
}

Received: 23 November 2013/Accepted: 2 December 2013/Published online: 17 December 2013

(C) Italian Association of Nuclear Medicine and Molecular Imaging 2013

\begin{abstract}
Revolutionary discoveries in cancer genomics in the last 10 years and the development of rapid genomic sequencing have led to a sea change in our understanding of the genetic events contributing to malignant transformation of cells and maintenance of the malignant state. This new understanding of the cancer genome allows implementation of specific therapies to suppress tumor growth. This review summarizes current knowledge of tumor biology as a basis for molecular targeting of cancer for imaging and/or therapy purposes. Important molecular events related to tumor biology are presented, focusing, in particular, on the knowledge that can contribute to the development of molecular targeting processes related to important aspects of cancer growth/metastasis. We discuss the relevance of these events to tumor mass imaging, tumor neovasculature development, tumor hypoxia, cellular constituents and cellcell synergism of the tumor mass, the immunologic sanctuary of tumors, the metastatic process, oncogene and nononcogene addiction, driver mutations in cancer cells, the $\mathrm{PI} 3 \mathrm{~K} / \mathrm{AKT}$ and RAS/ERK pathways, B-RAF inhibition, and carbonic anhydrase 9 in clear cell renal cancer. All this
\end{abstract}

Colour figures online at http://link.springer.com/article/10.1007/ 40336-013-0044-9.

\section{S. M. Larson $(\bowtie) \cdot$ H. W. Strauss}

Molecular Imaging and Therapy Service, Memorial Sloan

Kettering Cancer Center, 1275 York Avenue, New York,

NY 10065, USA

e-mail: LarsonS@MSKCC.ORG

H. W. Strauss

e-mail: StraussH@MSKCC.ORG

G. Mariani

Regional Center of Nuclear Medicine, University of Pisa, Via

Roma 67, 56126 Pisa, Italy

e-mail: giuliano.mariani@med.unipi.it knowledge, which can be encompassed by the general term metabolomics, can translate into practical applications for imaging the cancer cell phenotype. There is no doubt that this kind of precision medicine will increase the capacity of molecular imaging to monitor tumor-specific targeted treatments and determine the point in time when the cancer mutates again and escapes drug control.

Keywords Oncogenes - Suppressor genes - Tumor neovasculature · Tumor hypoxia - Immunologic sanctuary in cancer - Driver mutations in cancer - Metabolomics in cancer

\section{Background on tumor cell biology}

Most genes that are directly linked to cancer causation fall into two categories: oncogenes, which, when mutated, are drivers of a process that leads to cancer; and suppressor genes, which must be disabled to permit expression of the malignant state. To date, 140 such genes (80 tumor suppressor genes and 60 oncogenes) have been identified in tumor genomes [1]. Oncogenes have received more attention from the molecular imaging community given that it is easier to image a molecule or molecular event that is additive or increased in relation to the tissue of origin. Examples include the oncogene mutations that lead to HER2 overexpression in breast cancer, $c$-Kit mutations in gastrointestinal stromal tumors (GIST), and mutations of the EGFR-encoding gene in brain tumors and lung cancers. Examples of suppressor genes include BRCA 1 and 2, whose mutations are associated with breast, ovarian, and pancreatic cancer; gene $p 53$, whose mutation is associated with breast, sarcoma, and brain tumors; and the $R B$ gene, whose mutation is associated with retinoblastoma [1,2]. 
Fig. 1 Major characteristics of malignant neoplasms (modified from Ref. [2]) (color figure online)

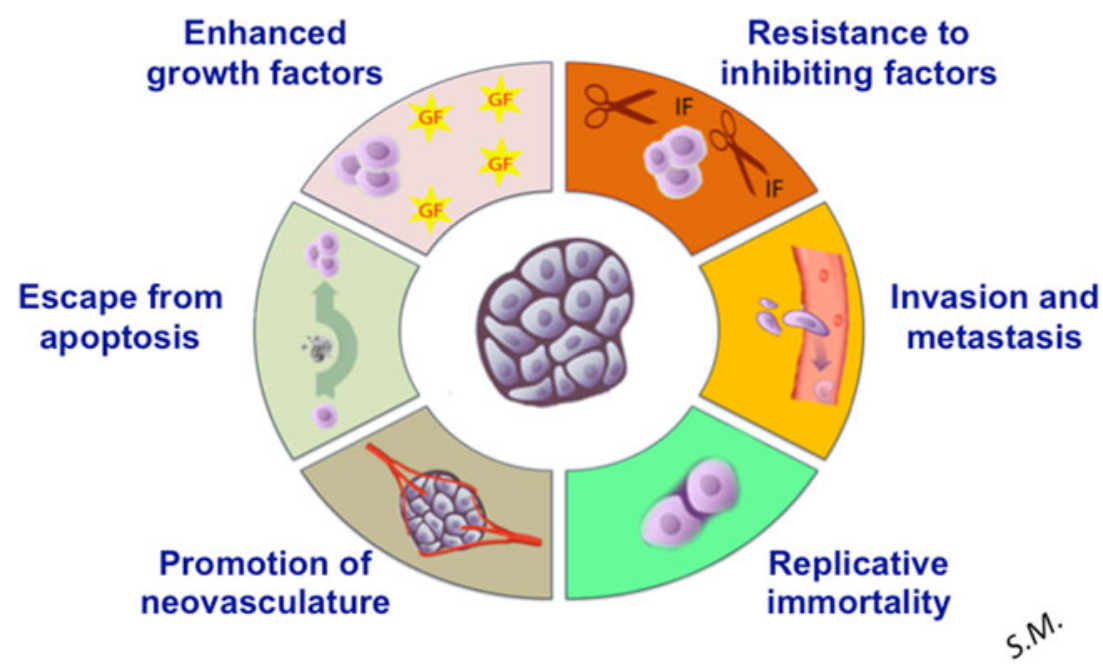

Tumor mass: a community of cells
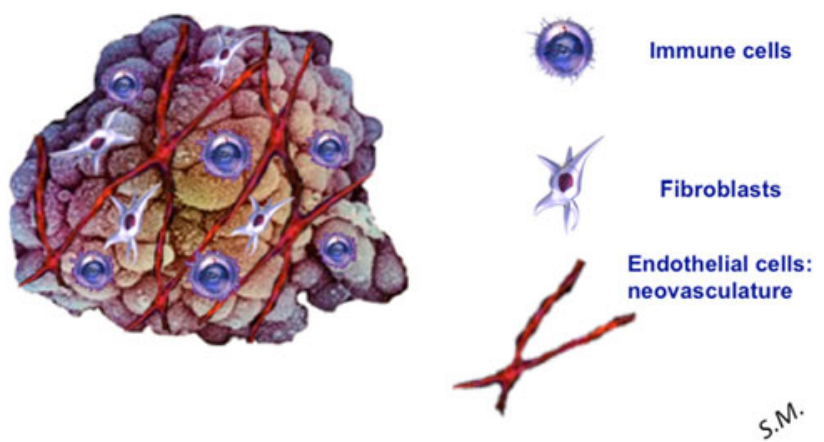

Fig. 2 The tumor mass comprised cancer cells and cells recruited from the host, such as fibrocytes, endothelial cells and immune cells (color figure online)

The genetic alterations associated with malignant transformation lead to a set of common phenotypes that are typical of the cancer cell. The characteristic properties of cancer cells have been summarized by Hanahan and Weinberg [2] (see Fig. 1). In particular, cancer cells often show (1) more rapid proliferation than normal cells in the organ, (2) resistance to death signals (such as apoptosis), (3) resistance to suppression of proliferation, (4) metastatic behavior, (5) resistance to immunologic attack, and (6) a variety of stress responses, including characteristic metabolic patterns (such as increased glucose utilization). In principle, each of these characteristic phenotypic alterations is associated with underlying key molecules that can be targeted with selective drugs (for therapy) and radiolabeled tracers (for imaging and/or therapy purposes). As will be discussed later, the stromal elements of the cancer mass, which are recruited from the host, also play an important permissive role in allowing these characteristic behaviors.
The tumor mass

A general property essential to the long-term growth of cancer cells is the recruitment of a supporting framework for the creation of the mass that characterizes clinical malignancies (see Fig. 2). Fibrocytes, endothelial cells serving to form vessels carrying nutrients, and immune cells are all common constituents of the tumor mass, identifiable on morphologic imaging (CT scans for example). Prior to the recruitment of blood vessels, the size of a tumor is limited by the diffusion distance of oxygen in tissues, which is about 100-200 $\mu \mathrm{m}$. Once a blood supply is established, the tumor mass can grow.

Imaging the tumor mass

Observation of changes in the size of a tumor mass has long been the basis for monitoring treatment response. For centuries, this was accomplished by palpation. However, the development of reproducible high-resolution crosssectional anatomic imaging techniques, such as CT, ultrasound and MRI, has allowed precise measurements of tumor dimensions, and these techniques now constitute the gold standard for treatment monitoring. Although such anatomic imaging techniques are objective, they have limitations. In most situations, they require, in order to guarantee reliable measurement of the lesion volume, an at least $1 \mathrm{~g}$ mass of tissue, which corresponds to about $10^{8}$ cells. The current criteria for measuring neoplastic lesions (Response Evaluation Criteria in Solid Tumors, RECIST 1.1) are derived from the measurement of two perpendicular diameters in up to five soft-tissue masses. For a partial response (PR), a $>30 \%$ reduction is required in the sum of long dimensions of up to two tumor lesions per organ, and for a complete response (CR) disappearance of all lesions is required. Progressive disease (PD) is defined by a $>20 \%$ 


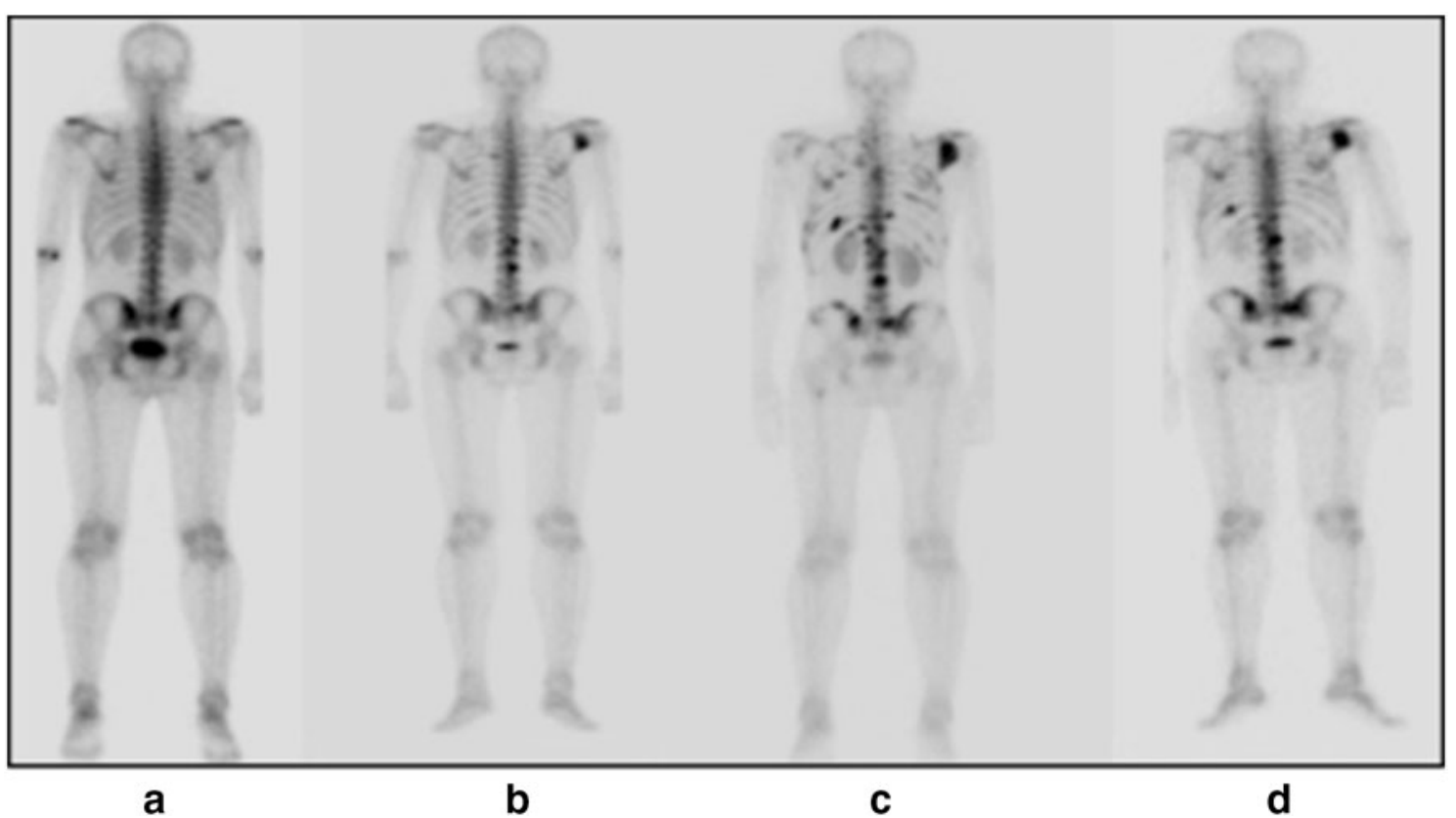

Fig. 3 Posterior views of serial bone scans of a patient with prostate cancer. Baseline a no metastasis; b 11 months later, demonstrating metastases in spine, ribs and scapula; c 3 months after b, demonstrating new lesions in the spine, ribs and pelvis, as well as increased

increase in the sum of long diameters, validated at 4 weeks after treatment.

Now, since the introduction of $\left[{ }^{18} \mathrm{~F}\right]$ FDG PET imaging, a metabolic measurement can be incorporated into the measurement of tumor response to treatment. On the basis of initial recommendations from the European Organization for Research and Treatment of Cancer (EORTC), a standardized uptake value (SUV) for $\left[{ }^{18} \mathrm{~F}\right] \mathrm{FDG}$, normalized to body weight $\left(\mathrm{SUV}_{\max }\right)$ [3], was used to define tumor metabolism as a parameter of response to treatment. In addition to $\mathrm{SUV}_{\max }$ (based on the pixel with the highest value in the tumor region of interest), glucose metabolism by the tumor mass can also be expressed using a region of interest of a defined size, which samples a larger number of pixels. The more recent "PET Response Criteria in Solid Tumors" (PERCIST) [4] system uses an SUV measure,

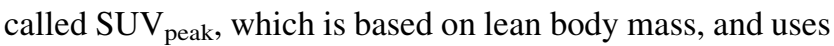
a circular region of $1.2 \mathrm{~cm}$ in diameter (sampling a region with an approximate mass of $1 \mathrm{~g}$ ) centered around the hottest voxel, over which the SUV is averaged. The SUVpeak based on lean body mass is called the SUL. PERCIST also applies an element of quality control to the metabolic evaluation, requiring that the $\mathrm{SUL}_{\text {peak }}$ in the lesion area be greater than the average SUL +2 standard deviations in the liver. In this way, comparison of the tumor and liver SUVs serves as a parameter for normalization of PET scans performed with different machines and in different conditions. An alternative approach recently proposed by Fox and extent of previously seen lesions; d 2 months later, following experimental therapy, there has been a decrease in the number and extent of osseous lesions

colleagues [5] uses semi-automated lesion tracking software to view all the lesions simultaneously in patients with advanced disease, since the size and metabolism of the total tumor burden is likely to be a valid measure of treatment response. Although efforts to develop an optimized approach to the quantitation of tumor metabolism are ongoing, the $\mathrm{SUV}_{\max }$ (corrected for body weight) remains one of the most robust measurements for this purpose.

\section{Neovasculature}

Once cancer cells are collected into a mass, they must recruit blood vessels in order to grow. The system of blood vessels in a tumor, called the "neovasculature", has several unique characteristics. The vessels are poorly organized, extremely permeable and often have an incomplete endothelial barrier. Most tumors have minimal lymphatics in the tumor mass (although lymphatic vessels are present at the periphery of the lesion); since the interstitial fluids have less possibility of draining out of the lesion through the lymphatic system, the tumor mass has a higher pressure than normal tissue, and this limits the diffusion, into the mass, of many molecules. From the radionuclide imaging and therapy point of view, poor diffusion within the tumor mass particularly affects macromolecules such as antibodies, which constitute the basis for a class of radiopharmaceuticals developed for radioimmunoscintigraphy, radioimmunoguided surgery, or radioimmunotherapy 
purposes (see most recent reviews in [6-22]). Conversely, the incomplete endothelial barrier of the neovasculature allows tumor cells to directly enter the host vasculature, and thus provides a path for these cells to circulate and metastasize.

Folkman [23], who was the first to recognize that inhibition of angiogenesis could inhibit tumor growth, coined the term "angiogenic switch" to refer to the moment when a small collection of tumor cells begins the vascularization process. Ferrara et al. [24] discovered the crucial role played by vascular endothelial growth factor (VEGF) in neovasculature development. In response to VEGF produced by tumor cells, stem cells are recruited from the bone marrow and migrate to the tumor mass, where they play an essential role in the production of the neovasculature. Agents that target either VEGF or its receptor include the antibody bevacizumab, and the peptides sorafenib and sunitinib. Bevacizumab binds VEGF, whereas the peptides interfere with the receptor. Both the antibody and the peptides show strong anti-tumor activity against some highly vascular tumors. Bevacizumab radiolabeled with zirconium-89 localizes in breast cancer [25]. In patients successfully treated with these agents, serial imaging with $\left[{ }^{18} \mathrm{~F}\right] \mathrm{FDG}$ PET shows a marked decrease in $\left[{ }^{18} \mathrm{~F}\right] \mathrm{FDG}$ uptake, reflecting the effectiveness of anti-VEGF therapy on tumor metabolism. The response of tumors to therapy with anti-angiogenesis drugs or to single-fraction high-dose radiation [26] has been linked to endothelial damage. In the case of single-fraction high-dose radiation, the therapy induces catastrophic apoptosis in endothelial cells which results in irreversible damage to tumors.

Unlike normal vessels, "leaky" neovasculature can be exploited to image the tumor mass. In fact, "leaky", incomplete endothelium allows both large molecules and nanoparticles to enter tumors, where they are retained. This process is called the "extravasation and passive retention" (EPR) effect, and it is thought to occur because larger molecules and nanoparticles enter the perivascular space through relatively large pores, but have difficulty getting back into the vasculature, rather in the way a lobster has trouble finding its way out of a lobster trap. The continuous expression of angiogenesis factors by the tumor causes a concomitant increased expression of integrin receptors (such as $\alpha_{v} \beta_{3}$ integrin and other members of the integrin family), thereby providing a homing signal for the cells mobilized to create the new blood vessels for the tumor. Agents binding to this integrin have been synthesized, and their radiolabeled counterparts have been shown to localize in sites of neovascularization in tumors [27] and in sites of inflammation, such as healing infarcts [28]. Other endothelial targets suitable for imaging include the prostatespecific membrane antigen (PSMA), which can be imaged with the radiolabeled antibodies J591 and 7E11-C5.3.
Furthermore, attempts to develop radioimmunotherapy using these agents are under way [29-32]. In a review by Schliemann and Neri [33], nine vascular targets were described for which antibodies have been developed.

\section{Hypoxia}

Solid tumors tend to outgrow their blood supply, a circumstance that causes cancer cells to become hypoxic. The reduced cellular oxygen content characteristic of hypoxia can be imaged using a class of compounds called nitroimidazoles [34]. ${ }^{18} \mathrm{~F}$-misonidazole is the one that has been used most often [35], although there are numerous alternatives being developed [36-38]. These compounds localize mainly by passive diffusion into the tumor. Once in the cell, nitroimidazoles undergo a single-electron reduction. In the presence of oxygen, the molecule is immediately reoxidized. As a result, the reoxidized molecule diffuses back out of normoxic tissue. In the presence of hypoxia, this reoxidation cannot occur, and the molecule is therefore trapped within the hypoxic but viable tissue. Hypoxia is a key property of tumors that reduces the effectiveness of radiation therapy. Well-oxygenated tissue is about three times more sensitive to radiation damage than hypoxic tissue. Some investigators suggest using ${ }^{18} \mathrm{~F}-$ misonidazole to image hypoxic regions within tumors [39], so as to allow a boost of radiation to the hypoxic region while minimizing damage to normal tissues [40].

Cellular constituents and cell-cell synergism of the tumor mass

The tumor mass contains a mixture of tumor cells and cells recruited from the adjacent normal tissues of the host, such as fibroblasts, collagen fibrils, and vascular endothelium. The amount of stroma is highly tumor dependent, with lesions such as lymphoma having relatively little stroma, and others, such as pancreatic cancers, having relatively few tumor cells and abundant stroma. In addition, tissue macrophages and other immune cells are represented in the mass. Typically, about $3 \%$ of the cellular mass is composed of endothelial cells.

The tumor mass cannot grow without the active synergy of each cellular component. There is evidence that cells interact with one another in several ways: small molecules, large molecular complexes, and entire pieces of membrane are exchanged between tumor cells and supporting stroma [41]. For example, P-glycoprotein, an ABC-transporter protein responsible for multidrug resistance, was shown to transfer from resistant to sensitive cells, as a functional entity, thereby allowing sensitive cells to acquire sufficient resistance to otherwise lethal levels of anti-cancer drugs. The notion that ${ }^{99 \mathrm{~m}} \mathrm{Tc}$-sestamibi, a well-established 
radiopharmaceutical widely employed for myocardial perfusion scintigraphy, is a substrate for the P-glycoprotein mechanism has opened the way for exploring the possibility of imaging multidrug resistance in vivo as a prognostic indicator of the tumor response to chemotherapy [42-44].

\section{Immunologic sanctuary}

In principle, neo-antigens and oncoproteins manufactured by the malignant cell should be more immunogenic than they actually are. Recent advances in knowledge of tumor biology with profound clinical implications have resulted in the development of antibodies with immune checkpoint blockade properties, such as ipilimumab (anti-CTLA4) and nivolumab (anti-PD1). These antibodies target molecules on tumor-specific T-cells which suppress this anti-tumor immunity. Both ipilimumab and nivolumab, both alone and in combination, have induced long-term remissions in $20-30 \%$ of very advanced and hitherto intractable solid tumors, such as melanoma and lung cancer [45]. Also, rituximab (an anti-CD20 antibody whose radiolabeled counterpart is employed for radioimmunotherapy) is a mainstay of immunotherapy for lymphomas, both alone and in combination with chemotherapy. These anti-tumor antibodies may induce immune cells to invade the tumor, post-treatment. This immunologic invasion, comprising predominantly $\mathrm{T}$-cells, can be intense enough to cause false-positive findings on $\left[{ }^{18}\right.$ F]FDG PET imaging [46]. Similar findings were observed after ipilimumab and nivolumab therapy, and in this case include increase in size of tumor mass because of immune cell infiltration and false positives on $\left[{ }^{18} \mathrm{~F}\right]$ FDG PET. For this reason, modified response criteria have been suggested for monitoring the response profile of solid tumors after these powerful immunologic treatments.

The metastatic process

Massague and colleagues passed human tumors through experimental animals to identify tumor cells with tropism for particular sites of metastasis, such as bone, brain and adrenals. In breast cancer, individual cells with this tropism were cloned and found to express specific molecules that enabled cells to migrate from the primary site and survive in the new environment [47-49]. Cells in a metastatic site may reseed the primary tumor, and vice versa, in a continuous exchange $[47,50]$. This process, which has been observed in animal models of melanoma and breast, colorectal and lung cancer, involves circulating tumor cells in the blood, including those which appear "differentiated" for tropism to specific tissues. This "tumor reseeding" may help explain why the growth of solid tumors follows Gompertzian kinetics, namely an

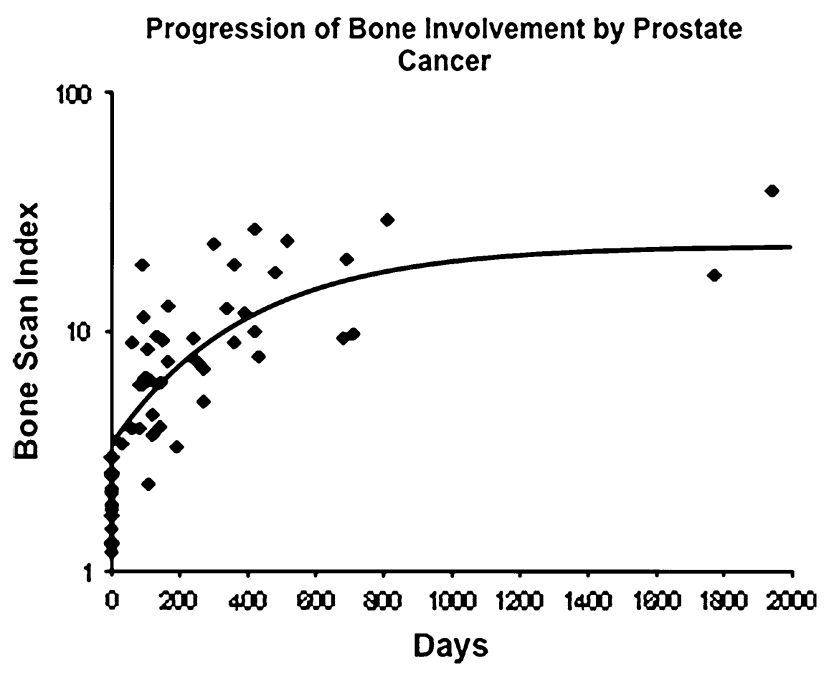

Fig. 4 Progression of metastases on bone scans of prostate cancer patients measured using the bone scan index (BSI) technique [56, 57]. The rate of progression of tumor in a group of patients followed a Gompertzian group curve, of the form, $\operatorname{BSI}(t)=\operatorname{BSI}_{0}(\exp (a / b(1-$ $\exp (-b t)))$ ) with an initial doubling time of 45 days, at $3 \%$ BSI involvement. Notice the characteristic decline in rate of growth, resulting in the reaching of a plateau. The initial metastases in these 27 patients occurred exclusively within the pattern of red marrow distribution in the adult male

exponentially declining growth trend in which the tumor doubling times are most rapid at the very earliest stage of tumor growth. Another feature of metastatic growth, which supports the concept that tumor cells seed organs via circulation in the blood, comes from studies in prostate cancer, in which the sites of early bone metastases were shown to correlate with the areas within the skeleton where active red bone marrow is present, i.e., where blood flow is particularly rich (see Fig.3). It was also observed in these patients that progression of tumor volume as a proportion of the bony skeleton (expressed by a bone scintigraphy index) follows a Gompertzian kinetic pattern (see Fig. 4).

Oncogene and non-oncogene addiction

Normal cells live within a particular tissue and receive growth and other control signals through a network of signal transduction molecules. In cancer cells, the process of intra-cellular communication may be co-opted by specific driver mutations in otherwise normal genes, a process which leads to an abnormal gene, the oncogene. Oncogenes produce abnormal gene products, oncoproteins, which drive oncogenesis, leading to malignant cell behavior. The mutation inducing overexpression of HER2 in breast cancer, $c$-Kit mutations in GIST, and mutation of the Abl kinase gene in leukemias are examples of driver mutations cited as examples of oncogene addiction. When mutations occur in the genes encoding kinases (such as EGFR) which 
Fig. 5 In the baseline ${ }^{124} \mathrm{I}-$ iodide PET/CT scan (upper row, coronal projection) arrows indicate sites of pulmonary metastases which do not take up radioiodine at $48 \mathrm{~h}$ after oral administration. In the lower image, taken 5 weeks later after treatment with the MEK inhibitor AZD 6244, all of these lesions have taken up sufficient amounts of radioiodine to predict therapeutic effect. Following therapy with ${ }^{131} \mathrm{I}$ iodide, this patient showed a reduction in size of pulmonary nodules as well as significant fall in serum thyroglobulin levels (data not shown) (color figure online)

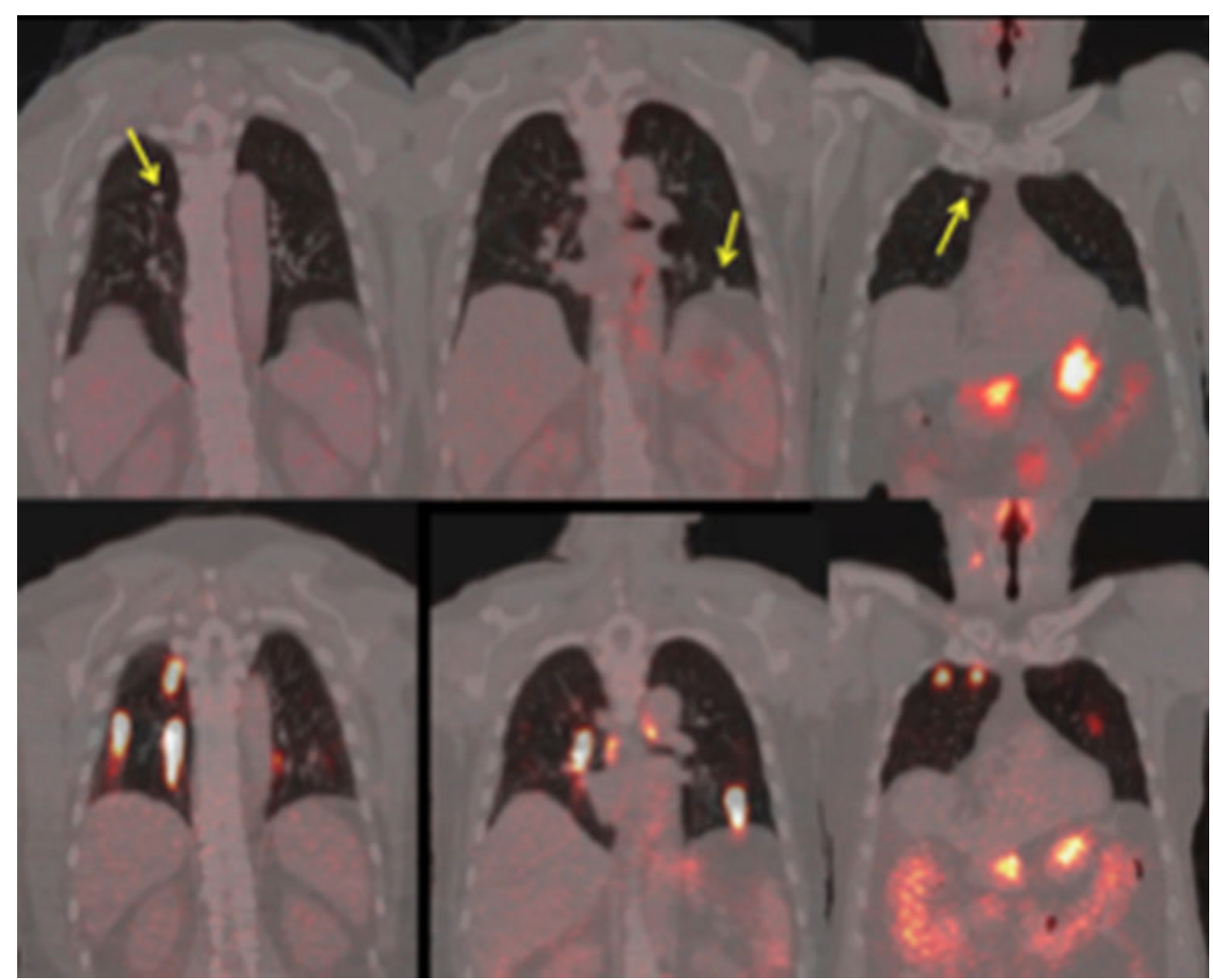

have a signal transmitting function, they can disrupt this function. Other commonly mutated oncogenes include genes controlling $\mathrm{Rb}, \mathrm{P} 53$, and PTEN, proteins that suppress a tendency toward tumor formation. In fact, cancer occurs when a series of mutations develop that cooperate to create the complex malignant phenotype.

\section{Driver mutations in cancer cells}

The mutations that drive the cancer cell into the malignant state can be divided into three categories: (1) gain-offunction mutations, (2) translocations, and (3) amplifications. Treatments and imaging are focused on these driver mutations, and in particular the success of kinase inhibitors has validated this approach.

\section{The PI3K/AKT and RAS/ERK pathways}

From the point of view of targeted drug therapy, the interaction of membrane receptor-based tyrosine kinase and the PI3K/AKT and the RAS/ERK pathways illustrates how a variety of drugs may inhibit signaling in specific ways. Molecular imaging with $\left[{ }^{18} \mathrm{~F}\right] \mathrm{FDG}$ is used to localize hypermetabolic tumor tissue at baseline and determine the response to pharmacologic blockade of the driver mutation.
B-RAF inhibition in advanced melanoma with V600E mutation

The highly specific tyrosine kinase inhibitor PLX 4032 is effective in patients with metastatic malignant melanoma. About $70 \%$ of melanomas show a significant response (based on RECIST 1.1 criteria) when treated with PLX 4032, as demonstrated in an early clinical trial in which 18 patients had a CR and 1 patient had a PR. The response was rapid, and characterized by a marked reduction of $\left[{ }^{18} \mathrm{~F}\right]$ FDG uptake. For therapy to be effective, PLX 4032 must be administered at a dose sufficient to inhibit $>80 \%$ of the B-RAF pathway [51].

Abnormalities of the B-RAF/ERK signaling pathway also promote the malignant state in thyroid cancer, and inhibition of MEK leads to re-differentiation of experimental models of human thyroid cancer in animals (James Fagin, personal communication, Sloan Kettering Institute). Patients with ${ }^{131}$ I-iodide refractory thyroid cancer were treated with the MEK inhibitor, AZD 6244 for 5 weeks and then restudied with quantitative PET imaging using iodine124. About $2 / 3$ of the patients had restoration of radioiodine uptake, and went on to be treated with ${ }^{131}$ I-iodide, showing an excellent clinical response to treatment (see Fig. 5). 


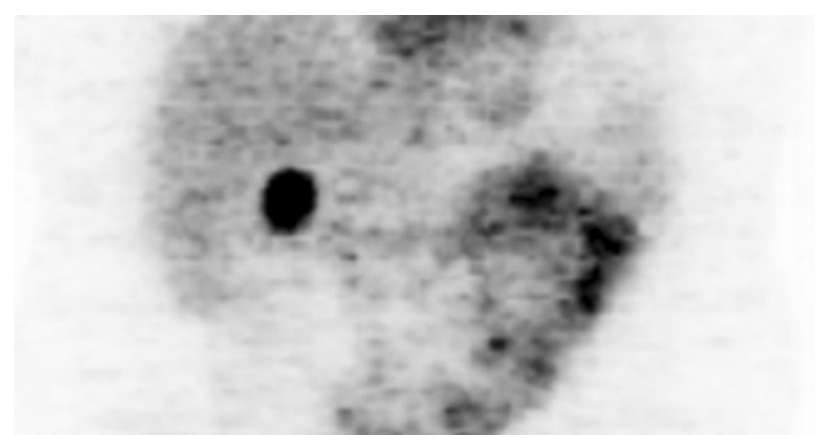

Fig. 6 Coronal view of ${ }^{124} \mathrm{I}-\mathrm{cG} 2506$ days post injection (see text for details)

Imaging of carbonic anhydrase 9 as a pathognomonic indicator of clear cell renal cancer

A driver mutation for the Von Hippel Lindau (VHL) protein occurs in renal cell cancer. At normal tissue oxygen levels, VHL tightly binds to and inactivates the transcription factor hypoxia-inducible factor- $1 \alpha$ (Hif- $1 \alpha)$. In renal cell cancer, there is an inactivating mutation of the VHLencoding gene, which means that Hif- $1 \alpha$ is continuously activated, leading to chronic production of downstream effector proteins (especially VEGFR), and also carbonic anhydrase 9 (CA9), these being proteins that are normally activated in hypoxic tissues. Clear cell renal cancer develops in this setting. ${ }^{124} \mathrm{I}-\mathrm{cG} 250$, a positron-emitting antibody which targets CA9, has been introduced to assist in surgical planning of masses of the kidney. Figure 6 shows uptake in a mass in the kidney bed with excellent contrast at 7 days after injection of ${ }^{124} \mathrm{I}-\mathrm{cG} 250$ [52]. Targeted therapy with sunitinib and sorefinib is used in this clinical setting to block the action of VEGFR.

There are many other examples of driver mutations, including those inducing androgen receptor activation in advanced castration-resistant prostate cancer. Androgen receptor inhibitors are an important component of therapy in these patients. The site(s) and extent of increased androgen receptor expression can be imaged with the radiofluorinated analog of testosterone, $16 \beta-{ }^{18} \mathrm{~F}$-dihydrotestosterone $\left({ }^{18} \mathrm{~F}-\mathrm{DHT}\right)$. Imaging with this tracer is particularly useful for determining the effectiveness of new anti-androgen receptor therapies.

\section{Imaging the cancer cell phenotype: metabolomics}

The term Warburg effect refers to a characteristic metabolic pattern of cancer, in which glycolysis is the dominant means of energy production, even in the presence of oxygen, and most of the carbon atoms from metabolism are secreted in the form of lactate [53]. This excessive glucose utilization by many tumors provides the rationale for the use of $\left[{ }^{18} \mathrm{~F}\right] \mathrm{FDG}$ PET/CT imaging to identify tumor sites and evaluate the impact of therapy. More than two million patients per year are imaged with $\left[{ }^{18} \mathrm{~F}\right] \mathrm{FDG}$ PET for the purpose of improving tumor staging, detecting recurrence and monitoring treatment response.

Warburg's initial observation was that proliferating tumor cells consume glucose at a higher rate compared to normal cells and that they secrete most of the glucosederived carbon in the form of lactate rather than oxidizing glucose completely. His initial hypothesis included the view that mitochondria must be defective in cancer cells, thereby providing a basis for the shift to aerobic glycolysis. Recent experiments indicate that, in most cancer cells at least, there is no problem with oxidative metabolism in mitochondria, and indeed that the conversion of pyruvate to lactate, based on the lactic dehydrogenase enzyme, is an important promoter of growth and tumorigenicity [1].

There is a growing awareness that the activation of aerobic glycolysis is just one of the metabolic programs crucial to the rapidly proliferating tumor cell. Others are lipid biosynthesis and glutamine dependent anaplerosis, the latter being a term used to describe replacement of intermediates within the Krebs cycle. The purpose of these metabolic flux pathways appears to be threefold: (1) to provide energy for the biochemical processes of growth and metabolism required by proliferating cells; (2) to provide the carbon backbone for key macromolecules such as nucleic acids, lipids and proteins; and (3) to help control the redox balance within the tumor cell. Signal transduction molecules and gene expressions have now been identified that are the natural regulators of these fluxes: the signal transduction pathways, especially the (PI $3 \mathrm{~K}) \backslash \mathrm{AKT} \backslash \mathrm{mTor}$ axis, as well as Hif- $1 \alpha$ and $M y c$, have emerged as some of the more important cellular modulators of metabolism [1].

Thus, a more complete picture of the altered metabolism of cancer cells is now emerging. The drivers of this altered metabolism include the relatively hypoxic tumor microenvironment with increased concentrations of Hif- $1 \alpha$, and oncogenic signaling through a variety of known oncogenes such as Ras and Myc. Suppressor proteins like P53 may also play a role. In fact, the P53 suppressor protein stimulates the gene encoding the synthesis of cytochrome $\mathrm{C}$ oxidase protein; therefore, when P53 is disabled by mutation there is direct interference with the mitochondrial respiratory chain. The altered metabolism confers certain advantages, such as increased biosynthesis of nucleotides, proteins, phospholipids and fatty acids; increased glycolysis also directly inhibits apoptosis by neutralizing reactive oxygen species through production of NADPH. However, this process also has disadvantages, considering that toxic metabolites such as lactate and non-canonical nucleotide species tend to accumulate. Finally, because of the high 
energy demand, alternative substrates such as fatty acids may need to be converted to ATP in order to meet the energy requirements of the cell.

Glutamine has recently been recognized as an essential nutrient for cell growth and for the viability of some cancers; in fact, tumor cells can become "addicted" to glutamine. In this circumstance, the tumor cell growth is fueled by a combination of glucose and glutamine. Whereas PI3K and AKT are the important signal transduction molecules which control glucose uptake, recent studies suggest that the $M y c$ oncogene may be crucial for the control of glutamine uptake. Glutamine plays a key role in the maintenance of Krebs cycle intermediates, as well as providing energy in the form of ATP. Thus, in the situation of active glutaminolysis, glucose and glutamine are the source of energy while most of the other substrates that are taken up contribute to the synthesis of macromolecules.

It is therefore clear that certain oncogenes with known functions, such as those encoding the receptor tyrosine kinases, interact with metabolism through the PI3K/AkT/ mTor pathway. PTEN, as a natural inhibitor of this pathway, might be expected to have a role in metabolic activation. Other tumor suppressor proteins such as P53 are also increasingly thought to play a role in modulating cancer cell metabolism, particularly by favoring oxidative phosphorylation and reducing glycolysis when active.

Additional metabolic enzymes which may have oncogenic function include fumarate hydratase (associated with leiomyosarcoma) and succinate dehydrogenase (associated with paraganglioma). When these enzymes are defective, there is accumulation of fumarate and succinate, respectively. An excess of these metabolites causes overexpression of Hif- $1 \alpha$, which in turn promotes tumor vascularization as well as increased glycolysis and may explain the tumor development. Recently, $70 \%$ of gliomas have been found to have mutations in isocitrate dehydrogenase enzymes (IDH1 and IDH2), thus suggesting a role for metabolic enzymes as oncogenes or tumor suppressors [54]. Mutations in the IDHI gene do not cause a loss of function but instead induce the ability to produce 2-hydroxyglutarate, a metabolite whose excess has been associated with malignancies in patients with inborn errors of 2-hydroxyglutarate metabolism [55].

\section{Future applications}

The development of radiotracer probes for molecular imaging research is continuing to proceed at a very rapid pace. Moreover, drug companies are recognizing the important role that molecular imaging, by allowing better understanding of the biology of the cancer process, can play in facilitating drug development. It is likely that ever more remarkable radiotracers, probably in combination with MRI agents and optical agents, will add to the information currently available from PET/CT. While many other molecular imaging approaches are available to characterize one or more aspects of a neoplasm, including proliferation (for instance with ${ }^{18} \mathrm{~F}$ fluoro-thymidine), apoptosis (with radiolabeled annexin), specific epitopes expressed on tumor cells (HER2 ligands), or amino acid incorporation (with trans-1-amino-3- $\left[{ }^{18} \mathrm{~F}\right]$ fluorocyclobutanecarboxylic acid, or ${ }^{18} \mathrm{~F}-\mathrm{ACBC}$ as a ligand for the glutamate receptor), it is likely that, due to the lengthy regulatory approval process, over the next 5 years $\left[{ }^{18} \mathrm{~F}\right] \mathrm{FDG}$ will continue to be the main radiopharmaceutical for evaluation of the tumor patient. In this regard, it is likely that, with increased understanding of changes in glucose transporter expression by the tumor cell, indices that are more sophisticated prognostic than $\mathrm{SUV}_{\max }$ will be developed. It is also likely that genomic analysis of circulating tumor cells may be used as a gatekeeper, to determine whether an $\left[{ }^{18} \mathrm{~F}\right] \mathrm{FDG}$ PET/ CT study is likely to provide clinically useful information.

Conflict of interest Steven M. Larson, Giuliano Mariani, H. William Strauss declare no conflict of interest with the present manuscript.

Ethical standard Results of original human and animal studies reported in this review paper have been obtained during investigations that had been approved by the appropriate ethical committee and have therefore been performed in accordance with the pertinent ethical guidelines (i.e., Declaration of Helsinki, as laid down in 1964 and revised in 2008).

\section{References}

1. Vogelstein B, Papadopoulos N, Velculescu VE, Zhou S, Diaz LA Jr, Kinzler KW (2013) Cancer genome landscapes. Science 339:1546-1558

2. Hanahan D, Weinberg RA (2011) Hallmarks of cancer: the next generation. Cell 144:646-674

3. Young H, Baum R, Cremerius U, Herholz K, Hoekstra O, Lammertsma AA, Pruim J, Price P (1999) Measurement of clinical and subclinical tumour response using $\left[{ }^{18} \mathrm{~F}\right]$-fluorodeoxyglucose and positron emission tomography: review and 1999 EORTC recommendations. European Organization for Research and Treatment of Cancer (EORTC) PET Study Group. Eur J Cancer 35:1773-1782

4. Wahl RL, Jacene H, Kasamon Y, Lodge MA (2009) From RECIST to PERCIST: evolving considerations for PET response criteria in solid tumors. J Nucl Med 50(Suppl 1):122S-150S

5. Fox JJ, Autran-Blanc E, Morris MJ, Gavane S, Nehmeh S, Van Nuffel A, Gönen M, Schöder H, Humm JL, Scher HI, Larson SM (2011) Practical approach for comparative analysis of multilesion molecular imaging using a semiautomated program for PET/CT. J Nucl Med 52:1727-1732

6. Tran L, Beijnen JH, Huitema AD (2009) The preparation of radiolabeled monoclonal antibodies for human use. Hum Antibodies 18:145-156

7. Sharkey RM, Chang CH, Rossi EA, McBride WJ, Goldenberg DM (2012) Pretargeting: taking an alternate route for localizing radionuclides. Tumour Biol 33:591-600 
8. Tiernan JP, Ansari I, Hirst NA, Millner PA, Hughes TA, Jayne DG (2012) Intra-operative tumour detection and staging in colorectal cancer surgery. Colorectal Dis 14:e510-e520

9. Bühler P, Wolf P, Elsässer-Beile U (2009) Targeting the prostatespecific membrane antigen for prostate cancer therapy. Immunotherapy 1:471-481

10. Boswell CA, Brechbiel MW (2007) Development of radioimmunotherapeutic and diagnostic antibodies: an inside-out view. Nucl Med Biol 34:757-778

11. Wu AM, Olafsen T (2008) Antibodies for molecular imaging of cancer. Cancer J 14:191-197

12. Wu AM (2009) Antibodies and antimatter: the resurgence of immuno-PET. J Nucl Med 50:2-5

13. Nayak TK, Brechbiel MW (2009) Radioimmunoimaging with longer-lived positron-emitting radionuclides: potentials and challenges. Bioconjug Chem 20:825-841

14. Artiko VM, Sobić-Saranović DP, Krivokapić ZV, Petrović MN, Obradović VB (2009) Is there a future role for immunoscintigraphy in the diagnosis of colorectal carcinoma? Neoplasma $56: 1-8$

15. Povoski SP, Neff RL, Mojzisik CM, O’Malley DM, Hinkle GH, Hall NC, Murrey DA Jr, Knopp MV, Martin EW Jr (2009) A comprehensive overview of radioguided surgery using gamma detection probe technology. World J Surg Oncol 7:11

16. Rose AC, Shenoy PJ, Garrett G, Seward M, Kucuk RA, Doksansky H, Nastoupil LJ, Flowers CR (2012) A systematic literature review and meta-analysis of radioimmunotherapy consolidation for patients with untreated follicular lymphoma. Clin Lymphoma Myeloma Leuk 12:393-399

17. Tomblyn MB, Katin MJ, Wallner PE (2013) The new golden era for radioimmunotherapy: not just for lymphomas anymore. Cancer Control 20:60-71

18. Huclier-Markai S, Alliot C, Varmenot N, Cutler CS, Barbet J (2012) Alpha-emitters for immuno-therapy: a review of recent developments from chemistry to clinics. Curr Top Med Chem 12:2642-2654

19. Seidl C, Essler M (2013) Radioimmunotherapy for peritoneal cancers. Immunotherapy 5:395-405

20. Chao MP (2013) Treatment challenges in the management of relapsed or refractory non-Hodgkin's lymphoma-novel and emerging therapies. Cancer Manage Res 5:251-269

21. Barbet J, Bardiès M, Bourgeois M, Chatal JF, Chérel M, Davodeau F, Faivre-Chauvet A, Gestin JF, Kraeber-Bodéré F (2012) Radiolabeled antibodies for cancer imaging and therapy. Methods Mol Biol 907:681-697

22. Prabhu S, Boswell CA, Leipold D, Khawli LA, Li D, Lu D, Theil FP, Joshi A, Lum BL (2011) Antibody delivery of drugs and radionuclides: factors influencing clinical pharmacology. Ther Deliv 2:769-791

23. Folkman J (1971) Tumor angiogenesis: therapeutic implications. N Engl J Med 285:1182-1186

24. Ferrara N, Houck KA, Jakeman LB, Winer J, Leung DW (1991) The vascular endothelial growth factor family of polypeptides. J Cell Biochem 47:211-218

25. Gaykema SB, Brouwers AH, Lub-de Hooge MN, Pleijhuis RG, Timmer-Bosscha H, Pot L, van Dam GM, van der Meulen SB, de Jong JR, Bart J, de Vries J, Jansen L, de Vries EG, Schröder CP (2013) ${ }^{89} \mathrm{Zr}$-bevacizumab PET imaging in primary breast cancer. J Nucl Med 54:1014-1018

26. Garcia-Barros M, Paris F, Cordon-Cardo C, Lyden D, Rafii S, Haimovitz-Friedman A, Fuks Z, Kolesnick R (2003) Tumor response to radiotherapy regulated by endothelial cell apoptosis. Science 300:1155-1159

27. Zhu Z, Miao W, Li Q, Dai H, Ma Q, Wang F, Yang A, Jia B, Jing X, Liu S, Shi J, Liu Z, Zhao Z, Wang F, Li F (2012) ${ }^{99 \mathrm{~m}} \mathrm{Tc}-$
3PRGD2 for integrin receptor imaging of lung cancer: a multicenter study. J Nucl Med 53:716-722

28. Stacy MR, Maxfield MW, Sinusas AJ (2012) Targeted molecular imaging of angiogenesis in PET and SPECT: a review. Yale J Biol Med 85:75-86

29. Yao D, Trabulsi EJ, Kostakoglu L, Vallabhajosula S, Joyce MA, Nanus DM, Milowsky M, Liu H, Goldsmith SJ (2002) The utility of monoclonal antibodies in the imaging of prostate cancer. Semin Urol Oncol 20:211-218

30. Osborne JR, Akhtar NH, Vallabhajosula S, Anand A, Deh K, Tagawa ST (2013) Prostate-specific membrane antigen-based imaging. Urol Oncol 31:144-154

31. Tagawa ST, Milowsky MI, Morris M, Vallabhajosula S, Christos P, Akhtar NH, Osborne J, Goldsmith SJ, Larson S, Taskar NP, Scher HI, Bander NH, Nanus DM (2013) Phase II study of Lutetium-177-labeled anti-prostate-specific membrane antigen monoclonal antibody J591 for metastatic castration-resistant prostate cancer. Clin Cancer Res 19:5182-5191

32. Osborne JR, Green DA, Spratt DE, Lyashchenko S, Fareedy SB, Robinson BD, Beattie BJ, Jain M, Lewis JS, Christos P, Larson SM, Bander NH, Scherr DS (2013) A prospective pilot study of ${ }^{89} \mathrm{Zr}$-J591/PSMA positron emission tomography (PET) in men with localized prostate cancer undergoing radical prostatectomy. J Urol. doi:10.1016/j.juro.2013.10.041

33. Schliemann C, Neri D (2007) Antibody-based targeting of the tumor vasculature. Biochim Biophys Acta 1776:175-192

34. Rajendran JG, Wilson DC, Conrad EU, Peterson LM, Bruckner JD, Rasey JS, Chin LK, Hofstrand PD, Grierson JR, Eary JF, Krohn KA (2003) $\left[{ }^{18} \mathrm{~F}\right]$ FMISO and $\left[{ }^{18} \mathrm{~F}\right] \mathrm{FDG}$ PET imaging in soft tissue sarcomas: correlation of hypoxia, metabolism and VEGF expression. Eur J Nucl Med Mol Imaging 30:695-704

35. Sato J, Kitagawa Y, Yamazaki Y, Hata H, Okamoto S, Shiga T, Shindoh M, Kuge Y, Tamaki N (2013) ${ }^{18}$ F-fluoromisonidazole PET uptake is correlated with hypoxia-inducible factor- $1 \alpha$ expression in oral squamous cell carcinoma. J Nucl Med 54:1060-1065

36. Bourgeois M, Rajerison H, Guerard F, Mougin-Degraef M, Barbet J, Michel N, Cherel M, Faivre-Chauvet A (2011) Contribution of $\left[{ }^{64} \mathrm{Cu}\right]$-ATSM PET in molecular imaging of tumour hypoxia compared to classical $\left[{ }^{18} \mathrm{~F}\right]-\mathrm{MISO}$ - a selected review. Nucl Med Rev Cent East Eur 14:90-95

37. Chitneni SK, Palmer GM, Zalutsky MR, Dewhirst MW (2011) Molecular imaging of hypoxia. J Nucl Med 52:165-168

38. Mendichovszky I, Jackson A (2011) Imaging hypoxia in gliomas. Br J Radiol 84(Spec 2):S145-S158

39. Tachibana I, Nishimura Y, Shibata T, Kanamori S, Nakamatsu K, Koike R, Nishikawa T, Ishikawa K, Tamura M, Hosono M (2013) A prospective clinical trial of tumor hypoxia imaging with ${ }^{18} \mathrm{~F}$ fluoromisonidazole positron emission tomography and computed tomography (F-MISO PET/CT) before and during radiation therapy. J Radiat Res 54:1078-1084

40. Haubner R (2010) PET radiopharmaceuticals in radiation treatment planning - synthesis and biological characteristics. Radiother Oncol 96:280-287

41. Osswald M, Winkler F (2013) Insights into cell-to-cell and cellto-blood-vessel communications in the brain: in vivo multiphoton microscopy. Cell Tissue Res 352:149-159

42. Del Vecchio S, Ciarmiello A, Salvatore M (2000) Scintigraphic detection of multidrug resistance in cancer. Cancer Biother Radiopharm 15:327-337

43. Mohan HK, Miles KA (2009) Cost-effectiveness of ${ }^{99 \mathrm{~m}} \mathrm{Tc}$-sestamibi in predicting response to chemotherapy in patients with lung cancer: systematic review and meta-analysis. J Nucl Med 50:376-381

44. Dizdarevic S, Peters AM (2011) Imaging of multidrug resistance in cancer. Cancer Imaging 11:1-8 
45. Page DB, Postow MA, Callahan MK, Allison JP, Wolchok JD (2013) Immune modulation in cancer with antibodies. Annu Rev Med (Epub ahead of print)

46. Alvarez Páez AM, Nogueiras Alonso JM, Serena Puig A (2012) ${ }^{18}$ F-FDG-PET/CT in lymphoma: two decades of experience. Rev Esp Med Nucl Imagen Mol 31:340-349

47. Comen E, Norton L, Massague J (2011) Clinical implications of cancer self-seeding. Nat Rev Clin Oncol 8:369-377

48. Kang Y, He W, Tulley S, Gupta GP, Serganova I, Chen CR, Manova-Todorova K, Blasberg R, Gerald WL, Massagué J (2005) Breast cancer bone metastasis mediated by the Smad tumor suppressor pathway. Proc Natl Acad Sci USA 102:1390913914

49. Minn AJ, Kang Y, Serganova I, Gupta GP, Giri DD, Doubrovin M, Ponomarev V, Gerald WL, Blasberg R, Massagué J (2005) Distinct organ-specific metastatic potential of individual breast cancer cells and primary tumors. J Clin Invest 115:44-55

50. Kim MY, Oskarsson T, Acharyya S, Nguyen DX, Zhang XH, Norton L, Massagué J (2009) Tumor self-seeding by circulating cancer cells. Cell 139:1315-1326

51. Bollag G, Hirth P, Tsai J, Zhang J, Ibrahim PN, Cho H, Spevak W, Zhang C, Zhang Y, Habets G, Burton EA, Wong B, Tsang G, West BL, Powell B, Shellooe R, Marimuthu A, Nguyen H, Zhang KY, Artis DR, Schlessinger J, Su F, Higgins B, Iyer R, D’Andrea K, Koehler A, Stumm M, Lin PS, Lee RJ, Grippo J, Puzanov I, Kim KB, Ribas A, McArthur GA, Sosman JA, Chapman PB, Flaherty KT, Xu X, Nathanson KL, Nolop K (2010) Clinical efficacy of a RAF inhibitor needs broad target blockade in BRAFmutant melanoma. Nature 467:596-599

52. Divgi CR, Pandit-Taskar N, Jungbluth AA, Reuter VE, Gönen M, Ruan S, Pierre C, Nagel A, Pryma DA, Humm J, Larson SM, Old LJ, Russo P (2007) Preoperative characterisation of clear-cell renal carcinoma using iodine-124-labelled antibody chimeric G250 ( $\left.{ }^{124} \mathrm{I}-\mathrm{cG} 250\right)$ and PET in patients with renal masses: a phase I trial. Lancet Oncol 8:304-310

53. Warburg O (1956) On the origin of cancer cells. Science 123:309-314

54. Thompson CB (2009) Metabolic enzymes as oncogenes or tumor suppressors. N Engl J Med 360:813-815

55. Dang L, White DW, Gross S, Bennett BD, Bittinger MA, Driggers EM, Fantin VR, Jang HG, Jin S, Keenan MC, Marks KM, Prins RM, Ward PS, Yen KE, Liau LM, Rabinowitz JD, Cantley LC, Thompson CB, Vander Heiden MG, Su SM (2009) Cancerassociated IDH1 mutations produce 2-hydroxyglutarate. Nature 462:739-744

56. Sabbatini P, Larson SM, Kremer A, Zhang ZF, Sun M, Yeung H, Imbriaco M, Horak I, Conolly M, Ding C, Ouyang P, Kelly WK, Scher HI (1999) Prognostic significance of extent of disease in bone in patients with androgen-independent prostate cancer. J Clin Oncol 17:948-957

57. Imbriaco M, Larson SM, Yeung HW, Mawlawi OR, Erdi Y, Venkatraman ES, Scher HI (1998) A new parameter for measuring metastatic bone involvement by prostate cancer: the Bone Scan Index. Clin Cancer Res 4:1765-1772 